\title{
Investigations of Hydrocarbon Species on Solid Catalysts by Inelastic Neutron Scattering
}

\author{
Longfei Lin ${ }^{1}$ - Qingqing Mei ${ }^{1} \cdot$ Xue Han $^{1} \cdot$ Stewart F. Parker ${ }^{2,3}$. Sihai Yang ${ }^{1}$ (i)
}

Accepted: 1 October 2020 / Published online: 26 October 2020

(c) The Author(s) 2020

\begin{abstract}
The status of surface species on solid catalysts during heterogeneous catalysis is often mysterious. Investigations of these surface species are crucial to deconvolute the reaction network and design more efficient catalysts. Vibrational spectroscopy is a powerful technique to study the interactions between surface species and the catalysts and infrared (IR) and Raman spectroscopies have been widely applied to study reaction mechanisms in heterogeneous catalysis. However, IR/Raman spectra are difficult to model computationally and important vibrational modes may be IR-, Raman- (or both) inactive due to restrictions by optical selection rules. Inelastic neutron scattering (INS) is another form of vibrational spectroscopy and relies on the scattering of neutrons by the atomic nucleus. A consequence of this is that INS is not subject to any optical selection rules and all vibrations are measurable in principle. INS spectroscopy has been used to investigate surface species on catalysts in a wide range of heterogeneous catalytic reactions. In this mini-review, we focus on applications of INS in two important fields: petrochemical reactions and $\mathrm{C} 1$ chemistry. We introduce the basic principles of the INS technique, followed by a discussion of its application in investigating two key catalytic systems: (i) the behaviour of hydrocarbons on metaloxide and zeolite catalysts and (ii) the formation of hydrocarbonaceous species on methane reforming and Fischer-Tropsch catalysts. The power of INS in studying these important catalytic systems is demonstrated.
\end{abstract}

Keywords Inelastic neutron scattering (INS) $\cdot$ Hydrocarbon oxidation · Olefin oligomerisation · Methane reforming · Fischer-tropsch synthesis

\section{Introduction}

Global economic development and our daily life heavily rely on petroleum resources. Fossil fuels such as gasoline and diesel provide power for industrial and social activities; light olefins and monoaromatic BTX (i.e., benzene, toluene, and xylenes) are feedstocks for producing adhesives, carpet, cosmetics, fertilisers, paints, rubber, fabrics and plastics [1].

Stewart F. Parker

stewart.parker@stfc.ac.uk

Sihai Yang

Sihai.Yang@manchester.ac.uk

1 Department of Chemistry, University of Manchester, Manchester M13 9PL, UK

2 ISIS Facility, STFC Rutherford Appleton Laboratory, Chilton OX11 0QX, Oxfordshire, UK

3 UK Catalysis Hub, Research Complex at Harwell, Harwell Science and Innovation Campus, Didcot OX11 0FA, Oxfordshire, UK
The petrochemical process involves a series of reactions, including cracking, oligomerisation, isomerisation, hydrogen transformation, aromatisation, coke formation and oxidation [2-5]. The limited reserves of fossil oil places an urgent driver to improve the efficiency of these reactions to make the best use of fossil oil. These reaction systems have been investigated by a wide range of techniques, such as infrared (IR) spectroscopy, Raman spectroscopy, X-ray diffraction (XRD), nuclear magnetic resonance (NMR) spectroscopy and so on. However, these techniques are not always sufficient to gain a comprehensive view of the behaviour of hydrocarbon molecules.

A sustainable future for our society relies on developing alternative carbon resources [6-8]. Coal, natural gas (87-98\% methane) and biomass are abundant resources on Earth $[9,10]$. Conversion of $\mathrm{C} 1$ resources derived from coal, natural gas and biomass to olefins and liquid fuels is attracting increasing interest $[11,12]$. In academia, C1 chemistry such as methane reforming and Fischer-Tropsch synthesis (FTS) are extensively studied. In industry, catalyst 
deactivation and coke formation are major limitations in these processes. To gain a fuller understanding of the mechanism of coke formation, conventional techniques such IR and Raman spectroscopy are often inadequate.

Over the past decade or two, inelastic neutron scattering (INS) spectroscopy has emerged as a powerful technique to study the areas of petrochemical processing and $\mathrm{C} 1$ chemistry. Catalysts used in these processes such as metals, metaloxides and zeolites have strong absorption in the infrared region below $\sim 1300 \mathrm{~cm}^{-1}$, which severely limits the spectral range of such studies [13]. However, these catalysts consisting of metal, $\mathrm{Si}, \mathrm{O}$ are almost transparent in INS, whereas the reactants, intermediates and products are hydrogenous compounds which are readily observable by INS. This arises because the incoherent neutron scattering cross-section of hydrogen is much larger than that of any other element in hydrogen-containing materials and hence the INS spectrum is dominated by modes involving hydrogen displacement. Thus, INS spectroscopy is a uniquely positioned technique for studying and developing these processes.

Here, we will review the recent applications of INS to reactions involving hydrocarbon species over catalysts based upon zeolites, metals and metal oxides in the fields of petrochemical process and $\mathrm{C} 1$ chemistry. We will show how INS provides key information about olefins/aromatics reactions on solid catalysts, which are hardly accessible by other techniques but are vitally important in understanding the reaction mechanisms. The study of surface species over catalysts for methane reforming and FTS by INS is discussed in detail, which demonstrates INS as a powerful method to provide insight into catalyst deactivation and informs future catalyst design. A brief introduction to the INS technique is firstly presented, followed by examples of INS studies taken from the recent literature. We focus on reactions involving hydrocarbon species in this mini-review, but the technique and approach are applicable to a wide spectrum of heterogeneous catalysts [14-34].

\section{Fundamental and Technical Aspects of the INS Technique}

The neutron is an uncharged particle with a mass closely matching that of a hydrogen atom (1.0087 atomic mass unit) [23]. It has wave-particle duality and for inelastic scattering processes it is conveniently regarded as a particle in incoherent INS [25] (although the wave-like properties are exploited for the energy analysis). Inelastic scattering of neutrons occurs when they collide with the atomic nucleus of the sample and both energy and momentum of the incident neutron are exchanged with the scattering atom. The relative intensity of the scattering from atom $l$, in the $v$ th mode at energy $\omega$ is given by $[23,25]$ :
$S^{n}\left(Q, \omega_{v}\right)=y \frac{\sigma}{4 \pi} \frac{\left(Q \cdot u_{v}\right)^{2 n}}{n !} \exp \left(-\left(Q \cdot u_{T o t}\right)^{2}\right)$

where $Q$ is the momentum transfer; $\omega_{v}$ is the $v$ th mode at transition energy $\omega ; n$ is the order of the transition, for example, $n=1$ is the fundamental mode, $n=2$ is for the first overtone or binary combination, $n=3$ is for the second overtone or ternary combination, and so on; $y$ is a linear scaling factor. $\sigma$ is the inelastic scattering cross section of the atom $l . u_{v}$ is the amplitude of motion of atom $l$ in mode $v . u_{\text {Tot }}$ is a sum of the amplitudes of motion of all the atoms over all the modes.

In the harmonic approximation, the amplitude of motion $u_{v}$ is given by:

$u_{v}^{2}=\frac{\hbar}{2 \mu \omega_{v}}$

where $\hbar$ is the reduced Planck constant $(h / 2 \pi), \mu$ is the reduced mass.

Figure 1 shows an indirect geometry spectrometer, TOSCA, at the ISIS Facility [23]. On this type of spectrometer, there is a fixed relationship between the energy and momentum transfer [23]. The number of molecules in the neutron beam, is subsumed into the scaling factor $y$. The inelastic scattering cross section $\sigma$ is both element- and isotope-dependent and is measured experimentally [35]. $u_{\text {Tot }}$ is the Debye-Waller factor, the influence of which can be minimised by carrying out the INS measurements at temperatures below $30 \mathrm{~K}$. For TOSCA-like spectrometers, the intensity of the INS spectrum is straightforwardly determined by the number of atoms in the neutron beam, the nature of the atoms $(\sigma, \mu)$ and the atom vibrational frequency. Thus, INS is a powerful technique to monitor the dynamics of molecules resulting from the change of vibrational frequency of a certain chemical bond caused by cleavage or formation of chemical bonds, which could give crucial insights into the reaction mechanisms. Because ${ }^{1} \mathrm{H}$ has the largest cross section $(\sigma)$ and the smallest mass $(\mu)$ of any of the elements (or isotopes), it dominates the scattering, which makes INS particularly suitable for investigating the evolution of hydrogenous species.

Due to the intrinsic properties of neutrons, INS has multiple advantages of practical value in comparison with optical spectroscopies such as IR and Raman [36-38]. (1) IR and Raman are optical techniques which obey selection rules, i.e. only IR/Raman active vibrations are measurable, whereas neutrons are scattered by nuclei, so INS is not subject to any optical selection rules and all vibrations (the whole range of the molecular vibrational spectrum, $0-4000 \mathrm{~cm}^{-1}$, is covered) are allowed and, in principle, measurable. (2) INS spectra can be readily and accurately modelled: the intensities are proportional to the concentration of elements in the sample and their cross-sections, and the measured INS 
Fig. 1 a Schematic of TOSCA at ISIS and $\mathbf{b}$ a cutaway drawing of an analyser module.

Reprinted from reference [23] with permission from Elsevier
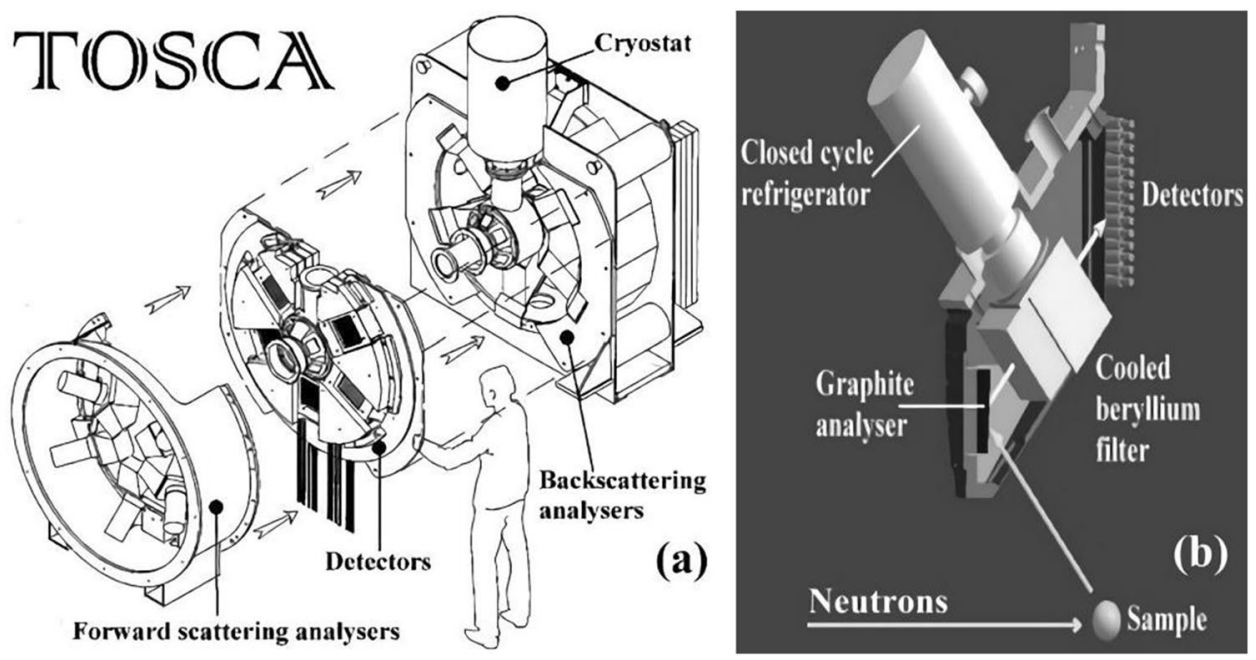

intensities relate directly to the associated displacements of the scattering atoms. This means that the calculation of INS spectra by DFT is often a much more reliable process than for other techniques, and the features in the spectra can be fully assigned. (3) Neutrons penetrate deeply into materials and pass readily through the walls of metal containers making cell design straightforward and neutrons ideal to measure bulk properties of the materials, which is particularly beneficial to detect species on the inner surface of porous catalysts.

\section{Conversions of Petrochemical Hydrocarbons}

\subsection{Oxidation of Hydrocarbons}

Oxidation of olefins is an important reaction both in academia and industry [39-41]. The oxidation of styrene attracts much interest because it produces useful chemicals, such as styrene oxide and benzaldehyde, that are intermediates in the manufacture of various fine chemicals and fragrances [42-44]. $\mathrm{MoO}_{2}$-based nanoparticle materials show promising catalytic performance for the oxidation of olefins [45]. During the synthesis of $\mathrm{MoO}_{2}$ nanoparticles, organic compounds are introduced as templating and reduction agents which would affect the catalytic oxidation performance. Calcination is not the preferred method to remove these organic reagents since such thermal treatment causes severe aggregation of nanoparticles. $\mathrm{MoO}_{2}$ has IR features between 600-1000 $\mathrm{cm}^{-1}$ [46], which may overlap with organic surface species, whereas $\mathrm{MoO}_{2}$ is almost transparent to INS spectroscopy. INS was deployed to investigate the effects of the outer shell of organic compounds on the catalysts in order to provide insights into the synthesis of efficient catalysts. Nanosized ${ }^{\mathrm{HQ}} \mathrm{MoO}_{2}$ synthesised by using ethylenediamine/hydroquinone, has a significant induction period for the catalytic oxidation of styrene, while ${ }^{\mathrm{Fe}} \mathrm{MoO}_{2}$ synthesised by using ethylenediamine/ $/ \mathrm{Fe}_{2} \mathrm{O}_{3}$ displays fast reaction kinetics [39]. The INS spectra of recovered ${ }^{\mathrm{Fe}} \mathrm{MoO}_{2}$ and ${ }^{\mathrm{HQ}} \mathrm{MoO}_{2}$ after reactions of $4 \mathrm{~h}$ show significant differences (Fig. 2a). By comparing the INS of the ${ }^{\mathrm{HQ}} \mathrm{MoO}_{2}$ before and after the reaction, it was found that only small amounts of product are formed (Fig. 2b). This is because ${ }^{\mathrm{HQ}} \mathrm{MoO}_{2}$ has a strongly surface-interacting organic shell (ethylenediamine/hydroquinone) on the particles, which suppresses the reaction. In contrast, the organic shell on ${ }^{\mathrm{Fe}} \mathrm{MoO}_{2}$ was only weakly surface-interacting and can be substituted easily during the reaction. As shown in Fig. 2c, recovered ${ }^{\mathrm{Fe}} \mathrm{MoO}_{2}$ catalyst showed the spectral features of styrene oxide and benzaldehyde. Thus, INS spectroscopy gives key insight into the catalysts and the oxidation reactions, promoting the future development of efficient catalysts for oxidation reactions.

\subsection{Olefin Oligomerisation}

Oligomerisation of olefins is one of the most important reactions in the petrochemical industry. This reaction attracts interest for the valorisation of light hydrocarbons, such as production of polypropylene. In addition, fluidised catalytic cracking (FCC) process includes a series of reactions, e.g., oligomerisation, $\beta$-scission and isomerisation, and thus oligomerisation critically affects the final products of FCC processes. In this context, the investigation of oligomerisation of olefins over solid acid catalysts is essential for the optimisation of petrochemical processes. Olefins and reaction intermediates are visible by INS while solid acids such as zeolites are transparent in INS. Moreover, INS spectra can be readily and accurately modelled (Sect. 2) which provides full assignment of INS peaks. Thus, INS has shown the ability to access the olefin oligomerisation reactions [47-49]. The mechanism of oligomerisation of propene 

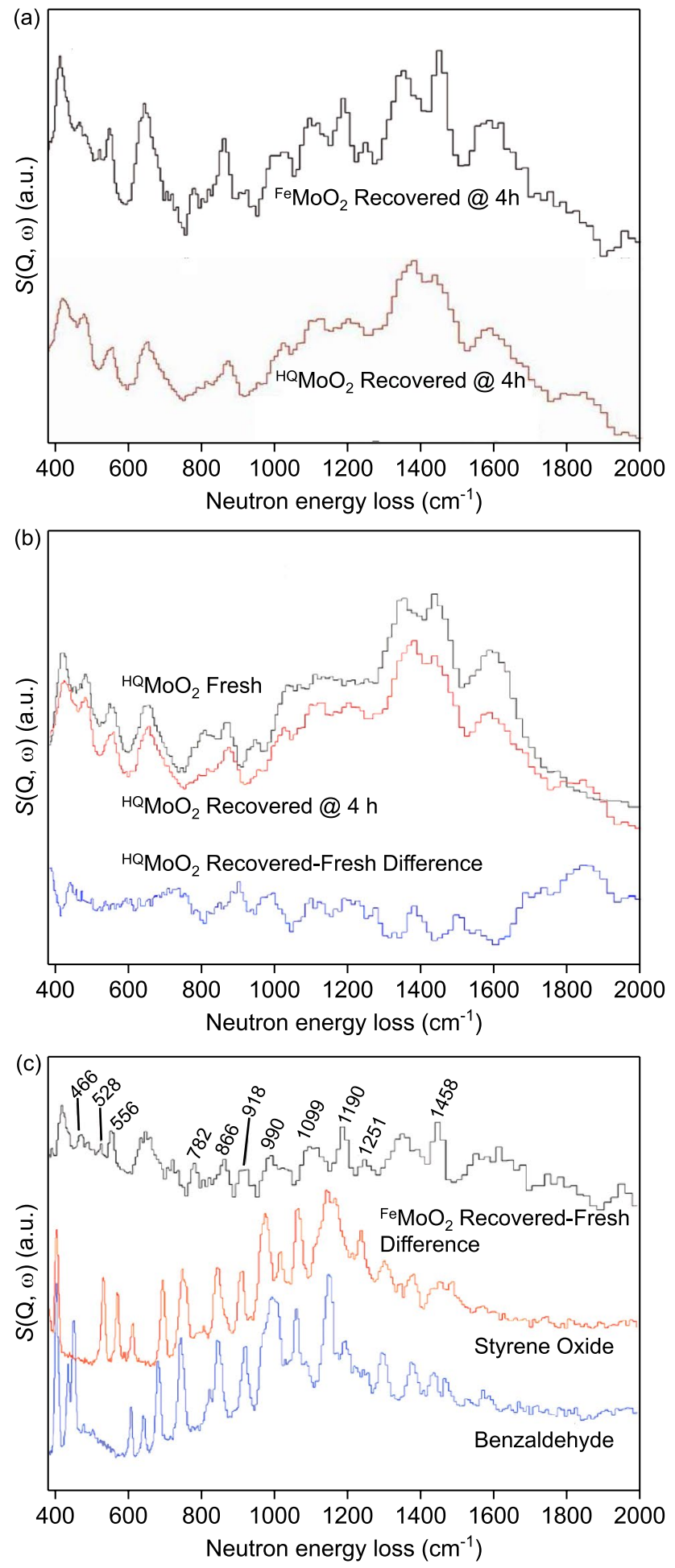

Fig. 2 a INS spectra of the ${ }^{\mathrm{Fe}} \mathrm{MoO}_{2}$ and ${ }^{\mathrm{HQ}} \mathrm{MoO}_{2}$ recovered catalysts after a $4 \mathrm{~h}$ styrene oxidation reaction at $353 \mathrm{~K}$. b Comparison of the INS spectra between fresh and recovered ${ }^{\mathrm{HQ}} \mathrm{MoO}_{2}$ catalysts. The corresponding difference spectrum is also shown. c Comparison of the difference INS spectrum found for the ${ }^{\mathrm{Fe}} \mathrm{MoO}_{2}$ catalyst (recovered@ $4 \mathrm{~h}$-fresh) and both styrene oxide and benzaldehyde products. The difference INS spectrum also shows labels for the bands assigned to the presence of both products. The INS spectra were recorded at $15 \mathrm{~K}$. Reproduced from reference [39] with permission from the PCCP Owner Societies

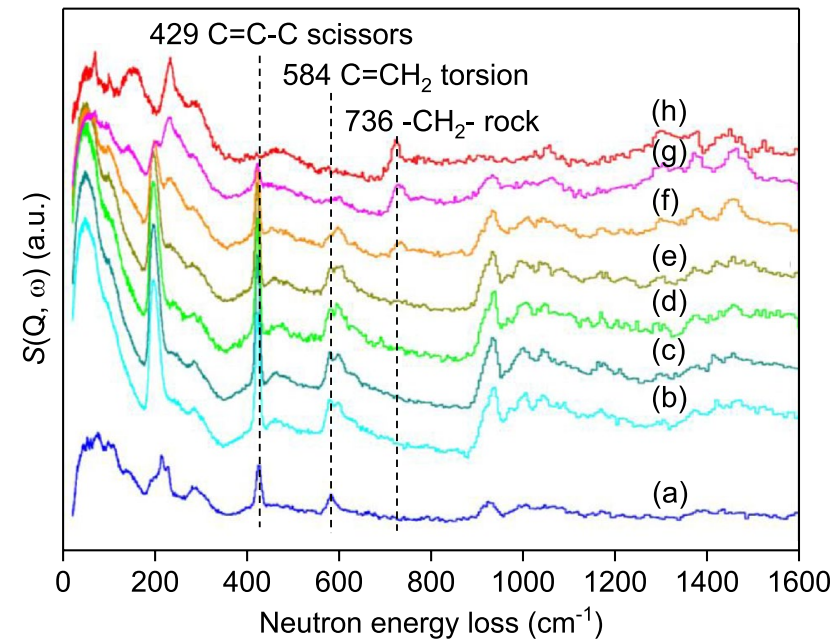

Fig. 3 TOSCA INS spectra of propene after absorption into ZSM-5 at $140 \mathrm{~K}$ a then following further heating to the indicated temperatures: $\mathbf{b}=200 \mathrm{~K} ; \mathbf{c}=215 \mathrm{~K} ; \mathbf{d}=225 \mathrm{~K} ; \mathbf{e}=240 \mathrm{~K} ; \mathbf{f}=255 \mathrm{~K} ; \mathbf{g}=270$ and $\mathbf{h}=293 \mathrm{~K}$. The INS spectra were recorded at $<25 \mathrm{~K}$. Reproduced from reference [47] published by the American Chemical Society

on HZSM-5 was clearly revealed by INS (Fig. 3) [47]. The spectrum of adsorbed propene at $140 \mathrm{~K}$ matches that of solid propene. Heating to $200 \mathrm{~K}$, the peak at $585 \mathrm{~cm}^{-1}$, assigned to the $\mathrm{C}=\mathrm{CH}_{2}$ torsion, splits into two peaks at 581 and $600 \mathrm{~cm}^{-1}$, indicating that the adsorbed propene is hydrogen bonded to a Brønsted acid site. On further heating to $255 \mathrm{~K}$, the intensities of peaks at $429(\mathrm{C}=\mathrm{C}-\mathrm{C}$ scissors $)$ and $584 \mathrm{~cm}^{-1}$ decrease, and a new mode assigned to $-\mathrm{CH}_{2}$ - rocking $\left(736 \mathrm{~cm}^{-1}\right)$ appears, suggesting the oligomerisation of $\mathrm{C}=\mathrm{C}$ to longer chains of hydrocarbons. Finally, at $293 \mathrm{~K}$, the complete oligomerisation of propene has occurred, and the INS spectrum is consistent with that of linear $\mathrm{C}_{44} \mathrm{H}_{90}$. Thus, the oligomerisation reaction proceeds via a three-step mechanism: (i) initial formation of hydrogen-bonded intermediates followed by (ii) protonation of the bound olefin to form a carbocation and (iii) subsequent oligomerisation continues through the hydride-shift mechanism to give a primarily linear product [47].

\section{C1 Chemistry}

\subsection{Methane Reforming}

It is widely acknowledged that fossil fuels on the earth will be depleted over the decades to come, enforcing people to develop new technologies based on other resources [8, 50, 51]. Currently, approximately 3900 billion cubic metres of natural gas are produced each year [52]. Natural gas mainly consists of methane (87-98\%) and the reforming of methane to syngas $\left(\mathrm{CO} / \mathrm{H}_{2}\right)$, which can be subsequently upgraded to 

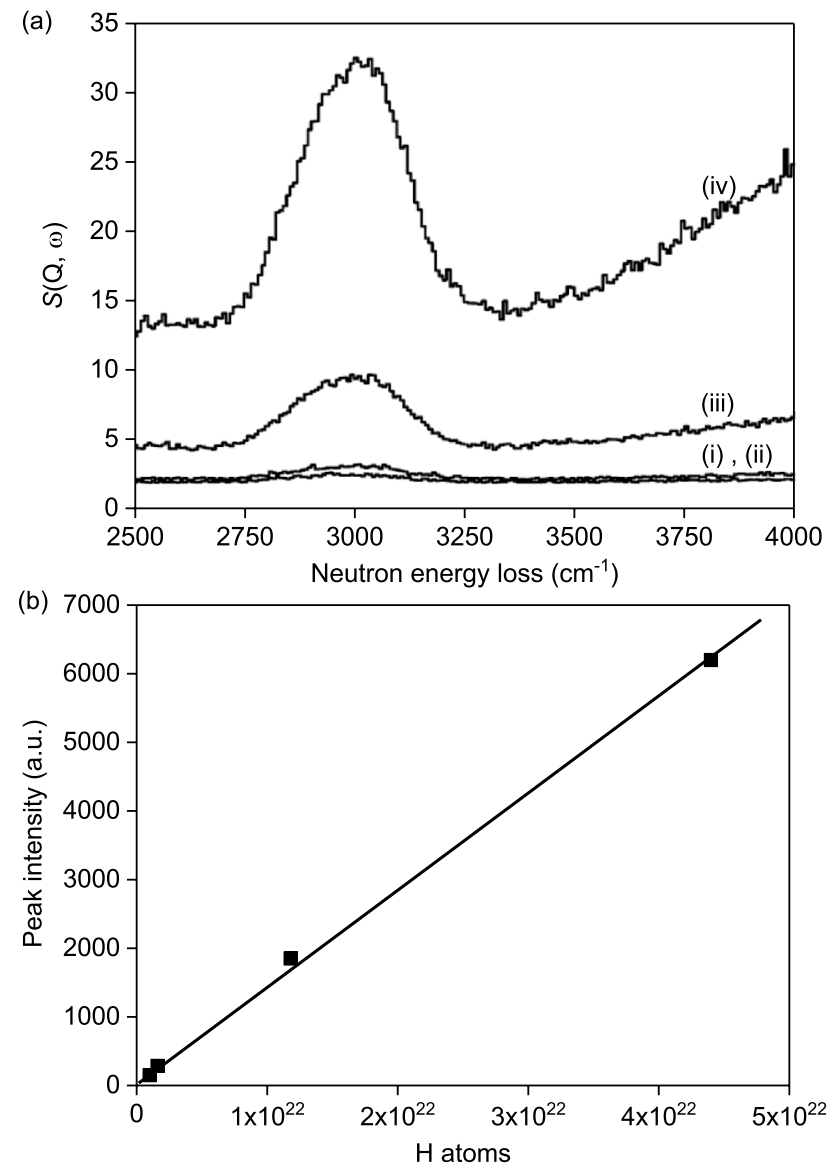

Fig. 4 a INS spectra of polystyrene recorded at $20 \mathrm{~K}$ in the region $2500-4000 \mathrm{~cm}^{-1}$ for four different masses of polystyrene: (i) $23 \mathrm{mg}$, (ii) $41 \mathrm{mg}$, (iii) $242 \mathrm{mg}$ and (iv) $969 \mathrm{mg}$. b A plot of integrated band intensity of the $n(C-H)$ mode of polystyrene as a function of the number of hydrogen atoms for a given mass. The straight line represents a linear least squares fit to the data (constrained through the origin), the slope of which defines the $\mathrm{n}(\mathrm{C}-\mathrm{H})$ sensitivity factor for the spectrometer operating in this configuration. Reproduced from reference [54] with permission from the PCCP Owner Societies

hydrocarbons by the Fischer-Tropsch process attracts much interest. Methane reforming can be carried out using either steam or $\mathrm{CO}_{2}$ as the oxidant, which are denoted as steam or dry reforming, respectively. Dry reforming requires less energy and has reduced environmental impact due to the consumption of $\mathrm{CO}_{2} \cdot \mathrm{Ni} / \mathrm{Al}_{2} \mathrm{O}_{3}$ is a highly active catalyst for both reforming methods. The stability of the catalyst is crucially important, and the challenge resides on gaining a detailed understanding of coke formation on spent catalysts, which is the major cause of deactivation. INS has been used to investigate hydrocarbonaceous overlayers on catalysts for methane reforming [53-59].

A new method has been developed to quantify the $\mathrm{C} / \mathrm{H}$ ratio of surface species on solid catalysts by INS, which is unachievable by IR spectroscopy [54]. Quantitative analysis

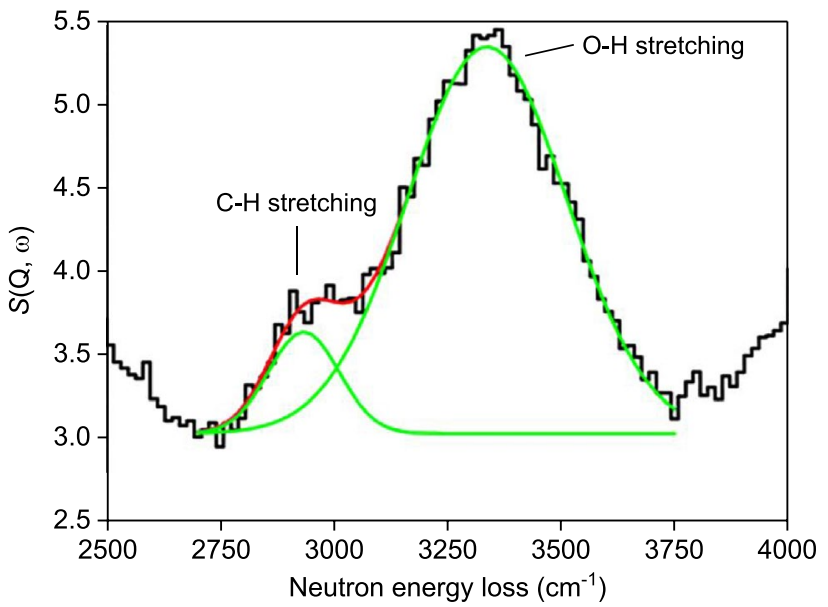

Fig. 5 The INS spectrum $\left(2500-4000 \mathrm{~cm}^{-1}\right)$ of the $45 \% \mathrm{Ni} / \mathrm{Al}_{2} \mathrm{O}_{3}$ catalyst after undergoing dry reforming of methane at $1073 \mathrm{~K}$ for $6 \mathrm{~h}$. The INS spectrum was recorded at $20 \mathrm{~K}$. The experimental data are well described by a combination of two Gaussian curves (green lines) centred at 2935 and $3339 \mathrm{~cm}^{-1}$, which are obtained from a non-linear least squares fitting procedure. The solid red line represents the overall fit. Reproduced from reference [54] with permission from the PCCP Owner Societies

by IR spectroscopy is difficult for adsorbed species which are unknown mixtures. Because the intensity of infrared absorption is determined by the interaction of electromagnetic radiation with the electrons i.e. with the electronic structure the extinction coefficient for a particular mode is a characteristic of the molecular species. This means that they cannot be transferred between molecules. INS spectroscopy overcomes this problem because the neutron interacts with the atomic nucleus rather than electrons. The observed intensity of an INS spectral band depends on density of oscillators and vibrational amplitude of oscillators; thus it is purely dynamic and the electronic structure is irrelevant. As the vibrational frequencies of $\mathrm{C}-\mathrm{H}$ oscillators in different molecular entities are similar, from Eq. (2), this means that the intensity per oscillator is the same, irrespective of the environment. Figure 4 shows the calibration results for the $\mathrm{C}-\mathrm{H}$ stretching mode using polystyrene $\left(\left[-\mathrm{CH}_{2} \mathrm{CH}\left(\mathrm{C}_{6} \mathrm{H}_{5}\right)-\right]_{\mathrm{n}}\right)$ as a reference material. The peak intensity is directly proportional to sample mass and the quality of fitting is highly convincing.

The INS spectrum of the $45 \% \mathrm{Ni} / \mathrm{Al}_{2} \mathrm{O}_{3}$ catalyst after undergoing dry reforming of methane at $1073 \mathrm{~K}$ for $6 \mathrm{~h}$ was measured (Fig. 5) [54]. The C-H stretching mode (peak center at $2935 \mathrm{~cm}^{-1}$ ) was observed. Based on the calibration coefficient (Fig. 4), the amount of hydrogen retained on the used $\mathrm{Ni} / \mathrm{Al}_{2} \mathrm{O}_{3}$ catalyst is $66 \mu \mathrm{mol} \mathrm{g}{ }^{-1}$ (cat). The amount of total carbon was measured by temperature programmed oxidation (TPO). The $\mathrm{C} / \mathrm{H}$ ratio was determined to be $160 / 1$, indicating that the catalyst is very efficient at cycling hydrogen. Realising the low extent of hydrogen retention on the catalyst provides valuable insights on understanding the side 


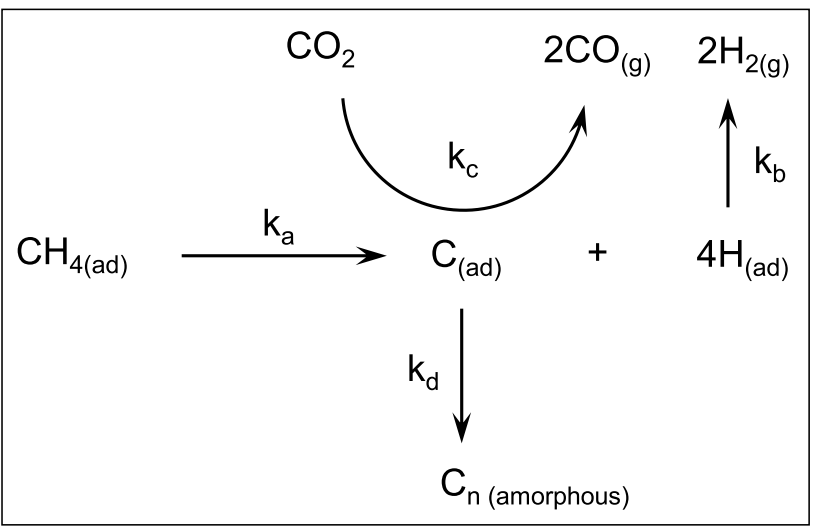

Fig. 6 Schematic representation of principal reactions affecting the partitioning of mass within the reaction system: a dissociative adsorption of methane, b re-combinative desorption of adsorbed hydrogen atoms, $\mathbf{c}$ oxidation of adsorbed carbon atoms and $\mathbf{d}$ polymerisation of adsorbed carbon to form amorphous carbon. The rate coefficients for these processes are respectively denoted $k_{a}, k_{b}, k_{c}$ and $\mathrm{k}_{\mathrm{d}}$. Reproduced from reference [55] with permission from the PCCP Owner Societies

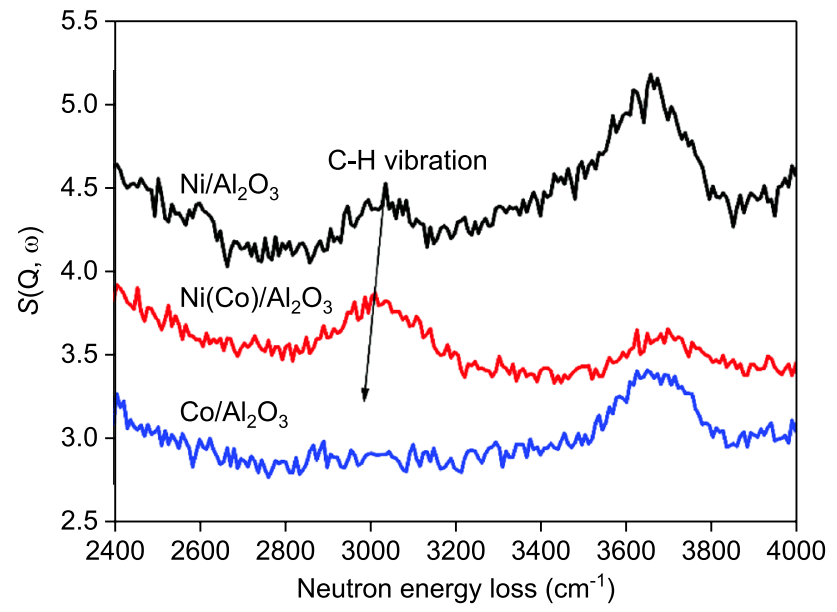

Fig. 7 INS spectra of spent catalysts using the MAPS spectrometer with an incident neutron energy of $4840 \mathrm{~cm}^{-1}$. The INS spectra were recorded at $20 \mathrm{~K}$. Reproduced from reference [58] with permission from the PCCP Owner Societies

reactions. As illustrated in Fig. 6, the associated rate coefficients exhibiting the following order: $\mathrm{k}_{\mathrm{b}} \gg \mathrm{k}_{\mathrm{d}}>\mathrm{k}_{\mathrm{c}}$ [55]. The detailed understanding of coke formation could lead to future design of coking-resistant catalysts.

In order to improve coking-resistance, Co was introduced into $\mathrm{Ni} / \mathrm{Al}_{2} \mathrm{O}_{3}$. After undergoing dry reforming of methane at $873 \mathrm{~K}$ for $6 \mathrm{~h}$, INS spectra of the $\mathrm{Ni} / \mathrm{Al}_{2} \mathrm{O}_{3}, \mathrm{Ni}(\mathrm{Co}) /$ $\mathrm{Al}_{2} \mathrm{O}_{3}$, and $\mathrm{Co} / \mathrm{Al}_{2} \mathrm{O}_{3}$ catalysts were collected (Fig. 7) [58]. The broad band at around $3000 \mathrm{~cm}^{-1}$ was assigned to $\mathrm{C}-\mathrm{H}$ stretching. The maxima at approximately 2950 and $3020 \mathrm{~cm}^{-1}$ corresponds to $\mathrm{C}-\mathrm{H}$ stretching modes of aliphatic and olefinic/aromatic hydrocarbon species, respectively [54].

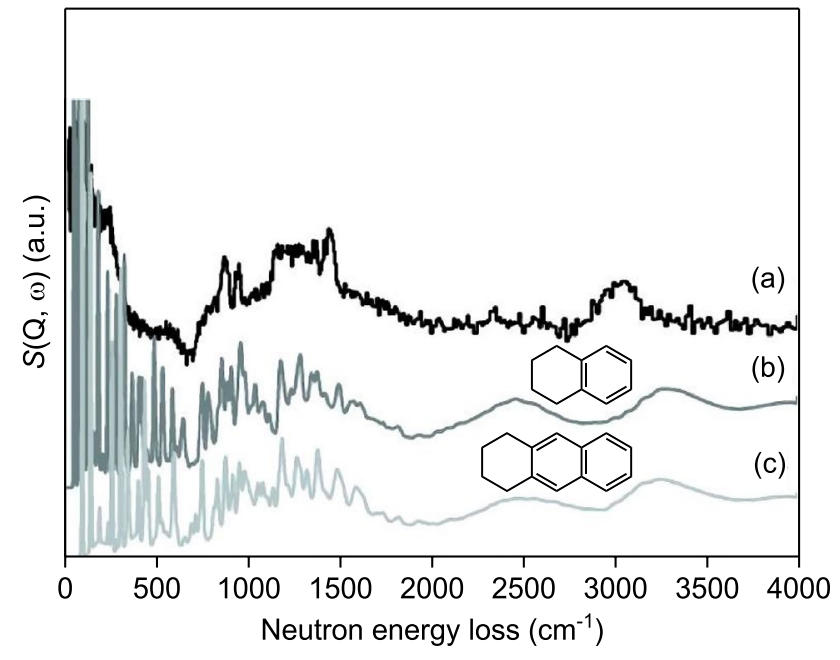

Fig. 8 Comparison of the measured INS spectrum of a FTS catalyst with simulated INS spectra of partially hydrogenated arenes. a Toluene extracted catalyst sample, b 1,2,3,4-tetrahydronaphthalene, and c 1,2,3,4-tetrahydroanthracene. The INS spectrum was recorded at $20 \mathrm{~K}$. Reproduced from reference [63] with permission from the Wiley-VCH Verlag GmbH \& Co. KGaA, Weinheim

The red-shift of the $\mathrm{C}-\mathrm{H}$ vibrations on used $\mathrm{Ni}(\mathrm{Co}) / \mathrm{Al}_{2} \mathrm{O}_{3}$ catalysts with respect to that for the used $\mathrm{Ni} / \mathrm{Al}_{2} \mathrm{O}_{3}$ catalysts indicates that the deposited species are mainly aliphatic compounds while on used $\mathrm{Ni} / \mathrm{Al}_{2} \mathrm{O}_{3}$ catalysts they are predominantly aromatic species. The used $\mathrm{Co} / \mathrm{Al}_{2} \mathrm{O}_{3}$ has only weak features at around $2900 \mathrm{~cm}^{-1}$ due to aliphatic species. These INS experiments demonstrated that cobalt in the bimetallic catalyst is responsible for depressing the deposition of aromatic carbons, thus minimising the permanent deactivation in dry reforming catalysis.

\subsection{Fischer-Tropsch Synthesis (FTS)}

FTS is a chemical reaction that converts syngas $\left(\mathrm{CO}+\mathrm{H}_{2}\right)$ into hydrocarbons, such as olefins, gasoline and diesel. Syngas may be generated from natural gas, coal, $\mathrm{CO}_{2}$ or biomass $[60,61]$ and FTS is considered as an alternative route towards the production of liquid fuels from more abundant resources, thereby remitting our existing reliance on fossil fuel. The most common catalysts for FTS are cobalt, iron, and ruthenium based solids [62]. INS has been employed to study the surface species on catalysts for $\mathrm{CO} / \mathrm{H}_{2}$ conversion in order to understand the reaction mechanism [17, 63-70].

Very significant advances in INS for FTS were achieved by Lennon et al. To obtain insights into the hydrogenous species present on an industrial, used catalyst, the team measured the INS spectrum of a technical-grade Fe-based FTS catalyst taken from a coal-to-liquids FTS plant in Secunda (South Africa) [63]. The spectrum of the used catalyst (Fig. 8) exhibits a series of distinct bands in the deformation 


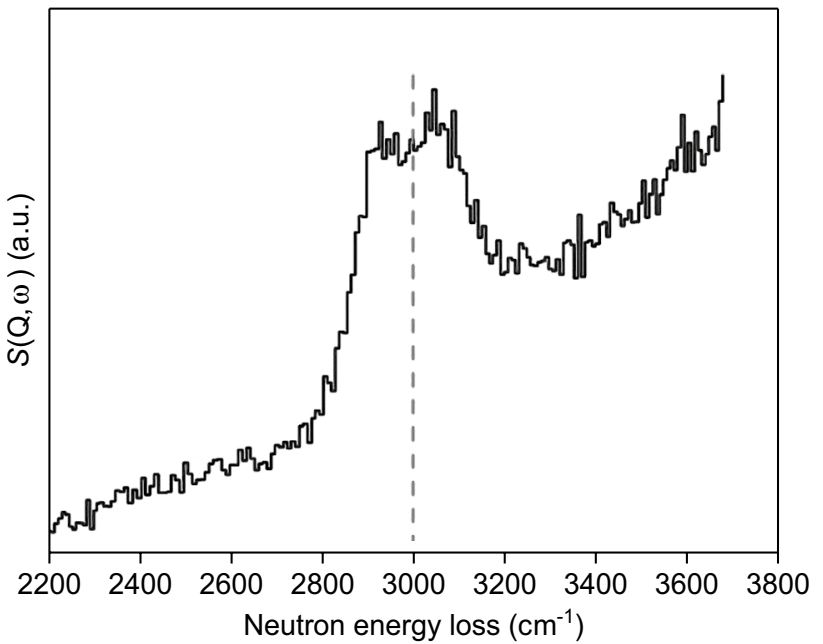

Fig. 9 INS spectrum of the toluene extracted catalyst sample in the $\mathrm{C}-\mathrm{H}$ stretch region obtained with the HET spectrometer. The INS spectrum was recorded at $20 \mathrm{~K}$. Reproduced from reference [63] with permission from the Wiley-VCH Verlag GmbH \& Co. KGaA, Weinheim

region $\left(\sim 800-1450 \mathrm{~cm}^{-1}\right)$ and a broad band in the $\mathrm{C}-\mathrm{H}$ stretch region $\left(\sim 3000 \mathrm{~cm}^{-1}\right)$. No mode characteristic of long-chain $-\left(\mathrm{CH}_{2}\right)_{\mathrm{n}}$ - units was observed at $\sim 720-730 \mathrm{~cm}^{-1}$, excluding the presence of long-chain aliphatic species. The band at $1441 \mathrm{~cm}^{-1}$ was assigned to the $-\mathrm{CH}_{2}$ - scissoring vibration of a cycloalkane and bands at deformation regions

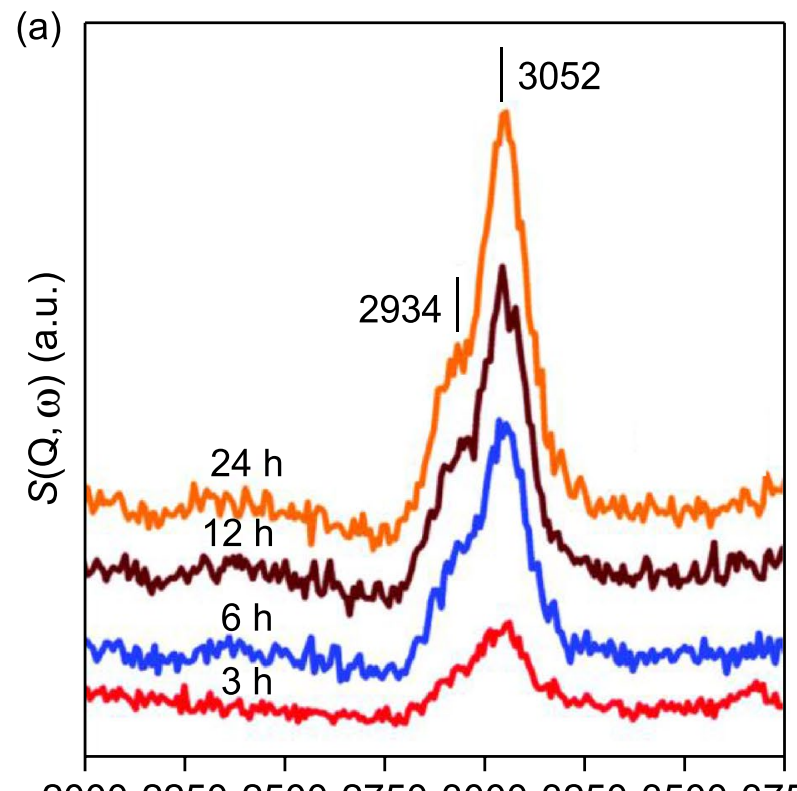

20002250250027503000325035003750 Neutron energy loss $\left(\mathrm{cm}^{-1}\right)$

Fig. 10 a INS spectra (recorded at $600 \mathrm{meV}, 20 \mathrm{~K}$ ) of the $\alpha-\mathrm{Fe}_{2} \mathrm{O}_{3}$ after $\mathrm{CO}$ hydrogenation at $623 \mathrm{~K}$ in the large scale reactor. b The quantified hydrogen content of the $2934 \mathrm{~cm}^{-1}$ (hollow) and
(800-1450 $\mathrm{cm}^{-1}$ ) are comparable to those in the calculated spectra of partially hydrogenated arenes. A high resolution INS spectrum in the $3000 \mathrm{~cm}^{-1}$ region obtained from the HET spectrometer (a direct geometry chopper instrument where the resolution is a function of the incident energy), implies approximately equal numbers of $\mathrm{sp}^{2}$ and $\mathrm{sp}^{3} \mathrm{C}-\mathrm{H}$ oscillators (Fig. 9). Thus, INS clearly revealed that the retained hydrocarbonaceous species on industrially relevant FTS catalyst are partially hydrogenated arenes rather than long-chain aliphatic species; the latter was previously believed to be the major coke component.

In analogy to the concept that hydrocarbonaceous overlayers can moderate the selectivity of branching in hydrogenation reactions over supported metal catalysts [71], the same team further studied the effects of hydrocarbonaceous species on the CO conversion by using lab-prepared FTS Fe-catalyst at milder reaction conditions (at 623-723 K and atmospheric pressure). The INS spectrum of the used catalyst is comparable to that of an iron catalyst extracted from a commercial grade FTS reactor, which validates the relevance of the adopted experimental approach [64-68]. Formation of the hydrocarbonaceous overlayer as a function of timeon-stream was monitored by INS (Fig. 10) [67]. Two peaks at 2934 and $3052 \mathrm{~cm}^{-1}$ assigned to $\mathrm{sp}^{3}$ and $\mathrm{sp}^{2} \mathrm{C}-\mathrm{H}$ stretch modes, respectively, were observed. The aliphatic $\mathrm{sp}^{3} \mathrm{C}-\mathrm{H}$ mode increases during the initial stages and saturates after ca. $8 \mathrm{~h}$ while olefinic/aromatic $\mathrm{sp}^{2} \mathrm{C}-\mathrm{H}$ species continually increase during the reaction.

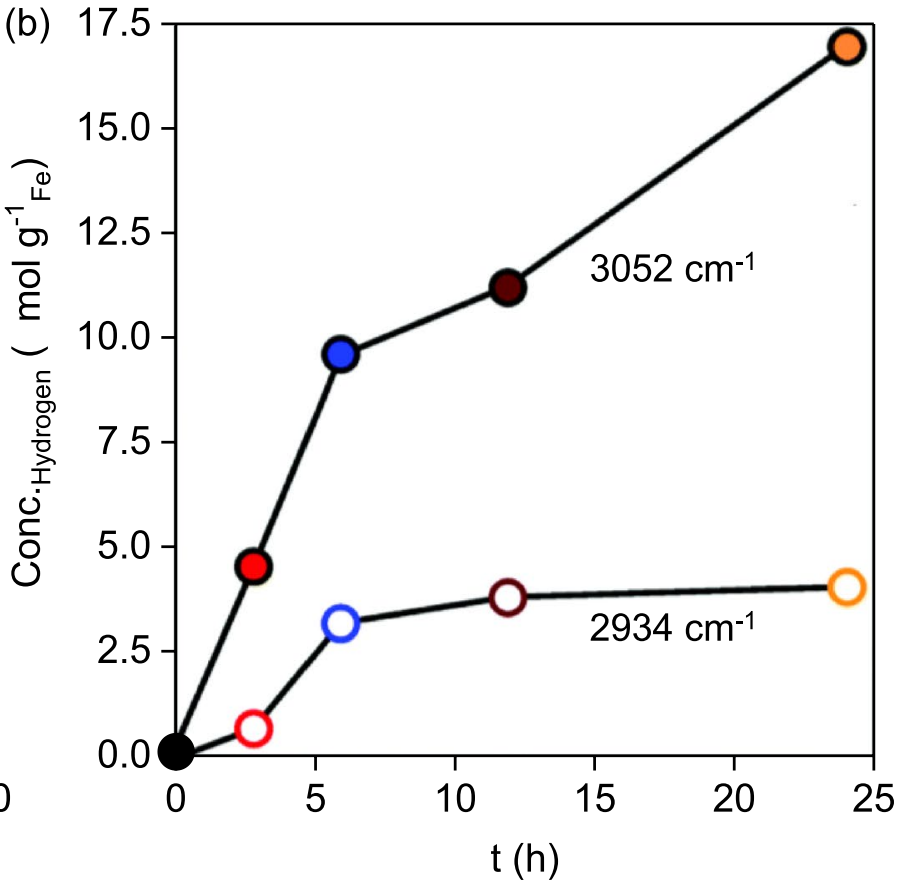

$3052 \mathrm{~cm}^{-1}$ (solid) features identified in part (a). Reproduced from reference [67] published by the Royal Society of Chemistry 


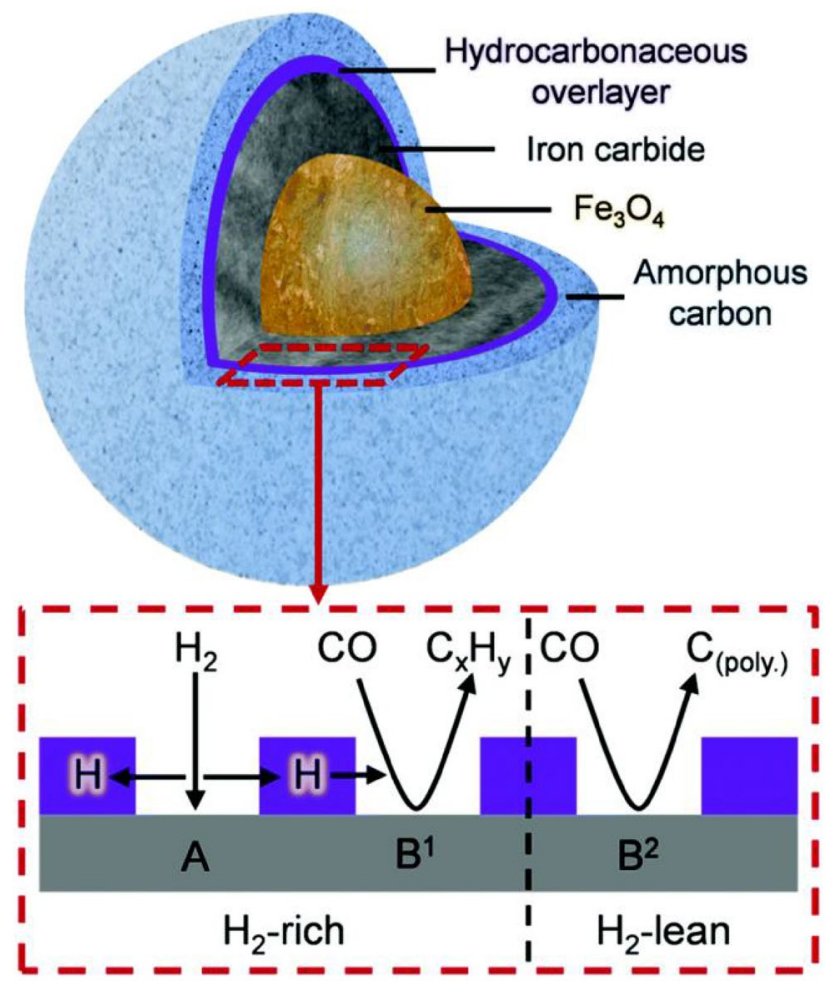

Fig. 11 A schematic indicating the composition of the Fe FTS catalyst after ca. $6 \mathrm{~h}$ ambient pressure $\mathrm{CO}$ hydrogenation at $623 \mathrm{~K}$. The hydrocarbonaceous overlayer (highlighted area) is suggested to mediate the transfer of hydrogen, where under $\mathrm{H}_{2}$-rich conditions, $\mathrm{C}_{\mathrm{x}} \mathrm{H}_{\mathrm{y}}$ prevails (site $\mathrm{B}^{1}$ ) whilst under $\mathrm{H}_{2}$-lean conditions, carbon polymerization occurs (site $\mathrm{B}^{2}$ ). Reproduced from reference [67] published by the Royal Society of Chemistry

A complete scheme of FTS catalyst evolution during the reaction was proposed by virtue of the insightful information provided by INS in combination with ex situ XRD, TPO and TEM (Fig. 11) [67]. Firstly, iron carbide forms which is the active phase in the reaction. Then a hydrocarbonaceous overlayer forms at the surface of the iron carbide. The coverage of the hydrocarbonaceous overlayer is partial, leaving two distinct 'open' sites A and B, which are associated with the dissociative adsorption of hydrogen and carbon monoxide to provide sources of hydrogen and chemisorbed carbon, respectively. Depending on the hydrogen supply from site $\mathrm{A}$, hydrocarbon products were formed where there is a rich and dynamic hydrogen supply (site $\mathrm{B}^{1}$ ) and amorphous/graphitic carbon is formed under hydrogen lean conditions ( site $\mathrm{B}^{2}$ ). Therefore, the hydrocarbonaceous overlayer characterised by INS may represent the precursor to both the desired FTS products and the undesired carbonaceous, or hard carbon.

\section{Conclusions}

The INS technique is ideally positioned to study hydrogenous species in heterogeneous catalysis owing to the remarkably high scattering cross-section of hydrogen. This minireview has presented recent achievements in characterising the hydrocarbon species with metal, metal-oxides and zeolite catalysts through INS and DFT calculations. These studies provide key information on the status of hydrocarbons adsorbed on catalysts during the reaction, which is hardly accessible by other techniques. Key steps within hydrocarbon reactions, such as adsorption, activation, cleavage and formation of chemical bonds, have been studied in detail by the INS technique. This new understanding provides insights into the reaction mechanisms and new perspectives to develop new, more efficient catalysts. With the rapid development of high performance computing facilities and flexible sample environment, INS spectroscopy combined with computational modelling will continue to reveal the mysteries of surface species on solid catalysts in wider fields of heterogeneous catalysis and promote the development of efficient catalytic processes.

Acknowledgements We thank EPSRC (Grant No. EP/P011632/1), the Royal Society and the University of Manchester for funding. QM is supported by a Royal Society Newton International Fellowship.

Open Access This article is licensed under a Creative Commons Attribution 4.0 International License, which permits use, sharing, adaptation, distribution and reproduction in any medium or format, as long as you give appropriate credit to the original author(s) and the source, provide a link to the Creative Commons licence, and indicate if changes were made. The images or other third party material in this article are included in the article's Creative Commons licence, unless indicated otherwise in a credit line to the material. If material is not included in the article's Creative Commons licence and your intended use is not permitted by statutory regulation or exceeds the permitted use, you will need to obtain permission directly from the copyright holder. To view a copy of this licence, visit http://creativecommons.org/licenses/by/4.0/.

\section{References}

1. Blay V, Epelde E, Miravalles R, Perea LA (2018) Converting olefins to propene: ethene to propene and olefin cracking. Catal Rev 60:278-335. https://doi.org/10.1080/01614940.2018.1432017

2. Giannetto G, Monque R, Galiasso R (1994) Transformation of LPG into aromatic hydrocarbons and hydrogen over zeolite catalysts. Catal Rev 36:271-304. https://doi.org/10.1080/0161494940 8013926

3. Cumming KA, Wojciechowski BW (1996) Hydrogen transfer, coke formation, and catalyst decay and their role in the chain mechanism of catalytic cracking. Catal Rev 38:101-157. https:// doi.org/10.1080/01614949608006455

4. Lin L, Qiu C, Zhuo Z et al (2014) Acid strength controlled reaction pathways for the catalytic cracking of 1-butene to propene over ZSM-5. J Catal 309:136-145. https://doi.org/10.1016/j. jcat.2013.09.011 
5. Hou Z, Han B, Zhang J et al (2003) n-Pentane isomerization in different phase regions near the critical temperature. J Supercrit Fluids 25:81-90. https://doi.org/10.1016/S0896-8446(02)00086-4

6. Shen X, Xin Y, Liu H, Han B (2020) Product-oriented direct cleavage of chemical linkages in lignin. ChemSusChem 13:43674381. https://doi.org/10.1002/cssc.202001025

7. Zhang Z, Song J, Han B (2017) Catalytic transformation of lignocellulose into chemicals and fuel products in ionic liquids. Chem Rev 117:6834-6880. https://doi.org/10.1021/acs.chemrev.6b004 57

8. Yang D, Zhu Q, Han B (2020) Electroreduction of $\mathrm{CO}_{2}$ in ionic liquid-based electrolytes. The Innovation 1:1-25. https://doi. org/10.1016/j.xinn.2020.100016

9. Kopyscinski J, Schildhauer TJ, Biollaz SMA (2010) Production of synthetic natural gas (SNG) from coal and dry biomass-a technology review from 1950 to 2009. Fuel 89:1763-1783. https ://doi.org/10.1016/j.fuel.2010.01.027

10. Mei Q, Liu H, Shen X et al (2017) Selective utilization of the methoxy group in lignin to produce acetic acid. Angew Chem Int Ed 56:14868-14872. https://doi.org/10.1002/anie.201706846

11. Roberts CB, Elbashir NO (2003) An overview to 'Advances in C1 chemistry in the year 2002'. Fuel Process Technol 83:1-9. https:// doi.org/10.1016/S0378-3820(03)00081-X

12. Zhou W, Cheng K, Kang J et al (2019) New horizon in C1 chemistry: breaking the selectivity limitation in transformation of syngas and hydrogenation of $\mathrm{CO}_{2}$ into hydrocarbon chemicals and fuels. Chem Soc Rev 48:3193-3228. https://doi.org/10.1039/C8CS0 $0502 \mathrm{H}$

13. Lennon D, McNamara J, Phillips JR et al (2000) An inelastic neutron scattering spectroscopic investigation of the adsorption of ethene and propene on carbon. Phys Chem Chem Phys 2:44474451. https://doi.org/10.1039/B005144F

14. Lin L, Sheveleva AM, da Silva I et al (2020) Quantitative production of butenes from biomass-derived $\gamma$-valerolactone catalysed by hetero-atomic MFI zeolite. Nat Mater 19:86-93. https://doi. org/10.1038/s41563-019-0562-6

15. Polo-Garzon F, Luo S, Cheng Y et al (2019) Neutron scattering investigations of hydride species in heterogeneous catalysis. Chemsuschem 12:93-103. https://doi.org/10.1002/cssc.20180 1890

16. O'Malley AJ, Parker SF, Catlow CR (2017) Neutron spectroscopy as a tool in catalytic science. Chem Commun 53:12164-12176. https://doi.org/10.1039/C7CC05982E

17. Albers PW, Lennon D, Parker SF (2017) Chapter 5 - catalysis. In: Fernandez-Alonso F, Price DL (eds) Experimental methods in the physical sciences. Academic Press, Boca Raton, pp 279-348

18. Parker SF, Lennon D (2016) Applications of neutron scattering to heterogeneous catalysis. J Phys Conf Ser 746:012066. https://doi. org/10.1088/1742-6596/746/1/012066

19. Lennon D, Parker SF (2014) Inelastic neutron scattering studies of methyl chloride synthesis over alumina. Acc Chem Res 47:1220-1227. https://doi.org/10.1021/ar400271c

20. Parker SF, Lennon D, Albers PW (2011) Vibrational spectroscopy with neutrons: a review of new directions. Appl Spectrosc 65:1325-1341. https://doi.org/10.1366/11-06456

21. Rhodes CJ (2010) Spectroscopic characterisation of molecules adsorbed at zeolite surfaces. Annu Rep Sect C 106:36-76. https ://doi.org/10.1039/B903505M

22. Ramirez-Cuesta AJ, Jones MO, David WIF (2009) Neutron scattering and hydrogen storage. Mater Today 12:54-61. https://doi. org/10.1016/S1369-7021(09)70299-8

23. Albers PW, Parker SF (2007) Inelastic incoherent neutron scattering in catalysis research. Adv Catal 51:99-132. https://doi. org/10.1016/S0360-0564(06)51003-X
24. Neumann DA (2006) Neutron scattering and hydrogenous materials. Mater Today 9:34-41. https://doi.org/10.1016/S1369 -7021(05)71336-5

25. Mitchell PCH, Parker S, Ramirez-Cuesta AJ, Tomkinson J (2005) Vibrational spectroscopy with neutrons: with applications in chemistry, biology, materials science and catalysis. World Scientific, Singapore

26. Albers P, Prescher G, Seibold K, Parker SF (1999) Applications of neutron scattering for investigating hterogeneous catalysts. Chem Eng Technol 22:135-137. https://doi.org/10.1002/(SICI)15214125(199902)22:2<135:AID-CEAT135>3.0.CO;2-4

27. Mitchell PCH (1994) Inelastic neutron scattering studies of catalysts. Acta Phys Hung 75:131-140. https://doi.org/10.1007/BF031 56567

28. Nicol JM (1992) Chemisorbed hydrogen and hydrogenous molecules. Spectrochim Acta Part A: Mol Spectrosc 48:313-327. https://doi.org/10.1016/0584-8539(92)80061-Z

29. Sheka EF (1991) Computational INS spectroscopy of dispersed catalysts. Phys B Condens Matter 174:227-232. https://doi. org/10.1016/0921-4526(91)90610-Q

30. Newsam JM, Brun TO, Trouw F et al (1990) Inelastic neutron scattering from non-framework species within zeolites. In: Baker RTK, Murrell LL (eds) Novel materials in heterogeneous catalysis. American Chemical Society, Washington, DC, pp 25-37

31. Dong L, Lin L, Han X et al (2019) Breaking the limit of lignin monomer production via cleavage of interunit carbon-carbon linkages. Chem 5:1521-1536. https://doi.org/10.1016/j.chemp r.2019.03.007

32. Xia Q, Chen Z, Shao Y et al (2016) Direct hydrodeoxygenation of raw woody biomass into liquid alkanes. Nat Commun 7:11162. https://doi.org/10.1038/ncomms 11162

33. Shao Y, Xia Q, Dong L et al (2017) Selective production of arenes via direct lignin upgrading over a niobium-based catalyst. Nat Commun 8:16104. https://doi.org/10.1038/ncomms16104

34. Wu Z, Cheng Y, Tao F et al (2017) Direct neutron spectroscopy observation of cerium hydride species on a cerium oxide catalyst. J Am Chem Soc 139:9721-9727. https://doi.org/10.1021/ jacs.7b05492

35. Munter A (2013) Neutron scattering lengths and cross sections. In: NIST Cent. Neutron Res. https://www.ncnr.nist.gov/resources/nlengths/. Accessed 14 Jun 2020

36. Yang S, Sun J, Ramirez-Cuesta AJ et al (2012) Selectivity and direct visualization of carbon dioxide and sulfur dioxide in a decorated porous host. Nat Chem 4:887-894. https://doi.org/10.1038/ nchem. 1457

37. Yang S, Ramirez-Cuesta AJ, Newby R et al (2015) Supramolecular binding and separation of hydrocarbons within a functionalized porous metal-organic framework. Nat Chem 7:121-129. https:// doi.org/10.1038/nchem. 2114

38. Han X, Godfrey HGW, Briggs L et al (2018) Reversible adsorption of nitrogen dioxide within a robust porous metal-organic framework. Nat Mater 17:691-696. https://doi.org/10.1038/s4156 3-018-0104-7

39. Nunes CD, Rudić S, Vaz PD (2020) Probing the relevance of $\mathrm{MoO}_{2}$ nanoparticles synthesis on their catalytic activity by inelastic neutron scattering. Phys Chem Chem Phys 22:896-904. https ://doi.org/10.1039/C9CP06278E

40. Sivadinarayana C, Choudhary TV, Daemen LL et al (2004) The nature of the surface species formed on $\mathrm{Au} / \mathrm{TiO}_{2}$ during the reaction of $\mathrm{H}_{2}$ and $\mathrm{O}_{2}$ : an inelastic neutron scattering study. $\mathrm{J} \mathrm{Am}$ Chem Soc 126:38-39. https://doi.org/10.1021/ja0381398

41. Wu L, Zhao S, Lin L et al (2016) In-depth understanding of acid catalysis of solvolysis of propene oxide over titanosilicates and titanosilicate $/ \mathrm{H}_{2} \mathrm{O}_{2}$ systems. J Catal 337:248-259. https://doi. org/10.1016/j.jcat.2016.01.028 
42. Mallat T, Baiker A (2004) Oxidation of alcohols with molecular oxygen on solid catalysts. Chem Rev 104:3037-3058. https://doi. org/10.1021/cr0200116

43. He J, Wu T, Hu B et al (2010) Bimetallic Au/Pd catalyzed aerobic oxidation of alcohols in the poly(ethylene glycol)/ $\mathrm{CO}_{2}$ system. Sci China Chem 53:1592-1597. https://doi.org/10.1007/s1142 6-010-4014-z

44. Han $\mathrm{H}$, Ding G, Wu T et al (2015) $\mathrm{Cu}$ and boron doped carbon nitride for highly selective oxidation of toluene to benzaldehyde. Molecules 20:12686-12697. https://doi.org/10.3390/molecules2 00712686

45. Bento A, Sanches A, Medina E et al (2015) $\mathrm{MoO}_{2}$ nanoparticles as highly efficient olefin epoxidation catalysts. Appl Catal Gen 504:399-407. https://doi.org/10.1016/j.apcata.2015.03.024

46. Naouel R, Touati F, Gharbi N (2012) Control of the morphology of molybdenum dioxide nanoparticles. E-J Chem 9:233-239. https ://doi.org/10.1155/2012/506572

47. Hawkins AP, Zachariou A, Parker SF et al (2020) Onset of propene oligomerization reactivity in ZSM-5 studied by inelastic neutron scattering spectroscopy. ACS Omega 5:7762-7770. https:// doi.org/10.1021/acsomega.9b03503

48. Hawkins AP, Zachariou A, Collier P et al (2019) Low-temperature studies of propene oligomerization in ZSM- 5 by inelastic neutron scattering spectroscopy. RSC Adv 9:18785-18790. https://doi. org/10.1039/C9RA03568K

49. Hawkins AP, O'Malley AJ, Zachariou A et al (2019) Investigation of the dynamics of 1-octene adsorption at $293 \mathrm{~K}$ in a ZSM-5 catalyst by inelastic and quasielastic neutron scattering. J Phys Chem C 123:417-425. https://doi.org/10.1021/acs.jpcc.8b08420

50. Zhang J, Qian Q, Wang Y et al (2019) Synthesis of ethanol from aryl methyl ether/lignin, $\mathrm{CO}_{2}$ and $\mathrm{H}_{2}$. Chem Sci 10:10640-10646. https://doi.org/10.1039/C9SC03386F

51. He Z, Cui M, Qian Q et al (2019) Synthesis of liquid fuel via direct hydrogenation of $\mathrm{CO}_{2}$. Proc Natl Acad Sci USA 116:1265412659. https://doi.org/10.1073/pnas.1821231116

52. International energy agency (2019) Natural gas information 2019. International energy agency, Paris

53. Silverwood IP, Hamilton NG, Staniforth JZ et al (2010) Persistent species formed during the carbon dioxide reforming of methane over a nickel-alumina catalyst. Catal Today 155:319-325. https ://doi.org/10.1016/j.cattod.2010.07.009

54. Silverwood IP, Hamilton NG, Laycock CJ et al (2010) Quantification of surface species present on a nickel/alumina methane reforming catalyst. Phys Chem Chem Phys 12:3102-3107. https ://doi.org/10.1039/B919977B

55. Silverwood IP, Hamilton NG, McFarlane AR et al (2012) Application of inelastic neutron scattering to studies of $\mathrm{CO}_{2}$ reforming of methane over alumina-supported nickel and gold-doped nickel catalysts. Phys Chem Chem Phys 14:15214-15225. https://doi. org/10.1039/C2CP42745A

56. R. McFarlane A, P. Silverwood I, Warringham R, et al (2013) The application of inelastic neutron scattering to investigate the 'dry' reforming of methane over an alumina-supported nickel catalyst operating under conditions where filamentous carbon formation is prevalent. RSC Adv 3:16577-16589. https://doi.org/10.1039/ C3RA42435A

57. McFarlane AR, Silverwood IP, Norris EL et al (2013) The application of inelastic neutron scattering to investigate the steam reforming of methane over an alumina-supported nickel catalyst. Chem Phys 427:54-60. https://doi.org/10.1016/j.chemphys.2013.10.012

58. Liao X, Gerdts R, Parker SF et al (2016) An in-depth understanding of the bimetallic effects and coked carbon species on an active bimetallic $\mathrm{Ni}(\mathrm{Co}) / \mathrm{Al}_{2} \mathrm{O}_{3}$ dry reforming catalyst. Phys Chem Chem Phys 18:17311-17319. https://doi.org/10.1039/C6CP01089J
59. Chinta S, Choudhary TV, Daemen LL et al (2002) Characterization of $\mathrm{C}_{2}\left(\mathrm{C}_{\mathrm{x}} \mathrm{H}_{\mathrm{y}}\right)$ intermediates from adsorption and decomposition of methane on supported metal catalysts by in situ INS vibrational spectroscopy. Angew Chem Int Ed 41:144-146. https ://doi.org/10.1002/1521-3773(20020104)41:1<144:AID-ANIE1 44>3.0.CO;2-J

60. Yang D, Zhu Q, Sun X et al (2020) Electrosynthesis of a defective indium selenide with $3 \mathrm{D}$ structure on a substrate for tunable $\mathrm{CO}_{2}$ electroreduction to syngas. Angew Chem Int Ed 59:2354-2359. https://doi.org/10.1002/anie.201914831

61. He M, Sun Y, Han B (2013) Green carbon science: scientific basis for integrating carbon resource processing, utilization, and recycling. Angew Chem Int Ed 52:9620-9633. https://doi. org/10.1002/anie.201209384

62. Zhang Q, Cheng K, Kang J et al (2014) Fischer-Tropsch catalysts for the production of hydrocarbon fuels with high selectivity. Chemsuschem 7:1251-1264. https://doi.org/10.1002/cssc.20130 0797

63. Hamilton NG, Silverwood IP, Warringham R et al (2013) Vibrational analysis of an industrial Fe-based Fischer-Tropsch catalyst employing inelastic neutron scattering. Angew Chem Int Ed 52:5608-5611. https://doi.org/10.1002/anie.201210179

64. Hamilton NG, Warringham R, Silverwood IP et al (2014) The application of inelastic neutron scattering to investigate $\mathrm{CO}$ hydrogenation over an iron Fischer-Tropsch synthesis catalyst. J Catal 312:221-231. https://doi.org/10.1016/j.jcat.2014.02.004

65. Warringham R, Hamilton NG, Silverwood IP et al (2015) The application of inelastic neutron scattering to investigate a hydrogen pre-treatment stage of an iron Fischer-Tropsch catalyst. Appl Catal Gen 489:209-217. https://doi.org/10.1016/j.apcat a.2014.10.033

66. Warringham R, McFarlane AR, MacLaren DA et al (2015) The application of inelastic neutron scattering to explore the significance of a magnetic transition in an iron based Fischer-Tropsch catalyst that is active for the hydrogenation of CO. J Chem Phys 143:174703. https://doi.org/10.1063/1.4935054

67. Warringham R, Davidson AL, Webb PB, Tooze RP, Ewings RA, Parker SF, Lennon D (2019) Examining the temporal behavior of the hydrocarbonaceous overlayer on an iron based FischerTropsch catalyst. RSC Adv 9:2608-2617. https://doi.org/10.1039/ C8RA09731C

68. Davidson AL, Webb PB, Parker SF, Lennon D (2020) Hydrogen partitioning as a function of time-on-stream for an unpromoted iron-based Fischer-Tropsch synthesis catalyst applied to CO hydrogenation. Ind Eng Chem Res 59:52-60. https://doi. org/10.1021/acs.iecr.9b04636

69. Wyvratt BM, Gaudet JR, Pardue DB et al (2016) Reactivity of hydrogen on and in nanostructured molybdenum nitride: crotonaldehyde hydrogenation. ACS Catal 6:5797-5806. https://doi. org/10.1021/acscatal.6b00936

70. Polo-Garzon F, Fung V, Nguyen L et al (2019) Elucidation of the reaction mechanism for high-temperature water gas shift over an industrial-type copper-chromium-iron oxide catalyst. J Am Chem Soc 141:7990-7999. https://doi.org/10.1021/jacs.9b03516

71. Kennedy DR, Webb G, Jackson SD, Lennon D (2004) Propyne hydrogenation over alumina-supported palladium and platinum catalysts. Appl Catal Gen 259:109-120. https://doi.org/10.1016/j. apcata.2003.09.018

Publisher's Note Springer Nature remains neutral with regard to jurisdictional claims in published maps and institutional affiliations. 